\title{
Hospital-to-Home Transition for Older Patients: Using Serious Games to Improve the Motivation for Rehabilitation - a Qualitative Study
}

\author{
Mirana Randriambelonoro ${ }^{1,2}$ (D) Caroline Perrin $^{1,2} \cdot$ Alexandra Blocquet $^{3}$. \\ Dominika Kozak ${ }^{4}$ - Julia Toyas Fernandez ${ }^{3}$ - Tiphaine Marfaing ${ }^{3}$. \\ Elisabeth Bolomey ${ }^{3} \cdot$ Zineb Benhissen $^{3} \cdot$ Emilia Frangos $^{3}$. \\ Antoine Geissbuhler ${ }^{1,2} \cdot{\text { Christophe } \text { Graf }^{3}}^{3}$
}

Received: 11 October 2019 / Accepted: 7 February 2020 / Published online: 19 February 2020

(C) The Author(s) 2020

\begin{abstract}
Traditional physiotherapy is often perceived as repetitive and boring by patients, leading to issues in maintaining their interest and performing the required exercises. This paper investigates older patients' engagement and motivation for physical activity using a serious game-based rehabilitation compared to a control group using a standard care therapy, during hospitalization. We conducted a randomized clinical trial with 57 geriatric patients and demonstrated that the serious game-based rehabilitation was as efficient as the standard rehabilitation program in terms of improving their functional capacity. In this paper, we mainly focus on reporting qualitative analysis of the patient's behavior change thorough the intervention. The intervention lasted 3 weeks. Semistructured interviews, including all the participants, were conducted before and after the intervention. Patients' attitudes towards rehabilitation process, physical activity and innovation technology were investigated. Motivation to be active following the intervention were explored. Participants admitted feeling bored at the hospital and only following along the care process routine. Enthusiasm towards the progress brought by technological solution was observed. At the end of the hospital stay, the serious gamebased rehabilitation received positive feedback. Patients felt more active and observed significant improvement of their general condition. The analysis suggests that patients participating in the gamified rehabilitation are more motivated. Several recommendations on designing serious game for elderly rehabilitation are proposed.
\end{abstract}

Keywords Serious Game · Elderly · Rehabilitation · Motivation · Engagement · Qualitative Study

Mirana Randriambelonoro

mirana.randriambelonoro@unige.ch

Extended author information available on the last page of the article 


\section{Introduction}

By 2050, one in six people in the world is expected to be part of the 65+ age group (United Nations 2019). This demographic shift towards a higher proportion of older people will increase the number of people at risk for disability (World Health Organization 2017). Indeed, elderly people are subject to more frequent and longer hospitalisation than younger ones due to the complexity of their illness, leading to a higher risk of functional decline (Covinsky et al. 2003; Kwok et al. 2016). A rehabilitation process is therefore necessary to restore geriatric patient's independence prior to returning home. Regular physical therapy increases muscle strength and functional capacities of hospitalized older people with musculoskeletal issues (Ling et al. 2017). However, it is often associated with frustration and poor adherence to the proposed exercise (Lang et al. 2009; Burke et al. 2009; Liddle et al. 2007) which represents a barrier for rehabilitation.

Recent technological developments paved the way to techniques that motivate behavior change, such as gamification. Gamification, defined as "the application of game principle into non-game context" (Huotari and Hamari 2012; Deterding et al. 2011), is being widely used in various domains such as work environment, marketing, education and health. The goal is to induce user engagement in performing certain actions. A plethora of research investigates the use of gamification to motivate physical exercise among people with chronic disease, cardiovascular risks and in the aging population (Hamari et al. 2014). Gamification principles are closely related to behavior change theories and techniques that have been demonstrated to improve health outcomes.

Promising evidence suggests the positive impact of gamification on motivation to be active (Johnson et al. 2016; Cugelman 2013; Lister et al. 2014). Researchers are designing persuasive technologies that motivate moderate physical activities. For example, to motivate people to walk more, activity monitoring devices are coupled with a virtual reward-system and allow users to collect badges and points (Skriloff et al. 2016). Another common area of research is the use of metaphors to help people visualize in a playful and easy way their progress towards their goal. Many studies have been trying to map the number of steps achieved to the growth of virtual characters such as animals (Lin et al. 2006) and plants (Consolvo et al. 2008). In addition, we observe a real interest in using serious game to engage people in performing physical exercise. Playing games that involve subtle physical movement are widely explored (Rice et al. 2011) not only for moderate activities like walking or running but also for rehabilitation exercises. Immersing the user into a virtual world does not only procure a feeling of pleasantness but also has the potential to increase user self-efficacy and confidence in doing the required exercise.

Previous research (Ling et al. 2017; Idriss et al. 2017; Brox et al. 2017) suggests that serious games increase motivation in rehabilitation sessions which consist of repetitive exercises. Game characteristics which generally involve cognitive and motor skills represent an effective way to retain elderly's attention (Krichevets et al. 1995) and distract them from pain and boredom (Burke et al. 2009). Furthermore, the possibility to increase the game level tailored to the patient's ability gives a sense of challenge followed by a feeling of satisfaction when achieving the task (Lumsden et al. 2016). Moreover, the emergence of (Kinect-based) motion detection technologies opens the way to the development of exergames (exercisebased videogames) for elderly people who are subject to frequent falls. Meekes and Stanmore (2017) found that social interaction was an important extrinsic motivator that increased the intrinsic motivation to adhere to the exergame program. Older people enjoyed playing the 
game and were more active and socially confident. This study had a small population size and was conducted in two living facilities quite different from a hospital context.

While gamification showed promising results, a systematic review of gamification usage in e-health (Sardi et al. 2017) emphasized the lack of valid empirical evidence in this field. In addition, serious game-based intervention is often associated with shortterm engagement mainly based on extrinsic rewards. Conditions for game engagement such as purpose, user alignment and utility need to be defined (El-Hilly et al. 2016) for gamification to reach its full potential. Finally, it remains unclear how gamification can be used to modify health behavior in a hospital setting while doing rehabilitation. Understanding the patient's context and how the gamified intervention could be aligned with their needs, during hospital stay, is therefore necessary.

This paper aims to determine whether and how the use of a gamified rehabilitation equipment adds value to the rehabilitation process, specifically in terms of engagement and motivation to increase physical activity.

\section{Methodology}

We conducted a randomized clinical trial and a qualitative study with 57 patients, 65+ years old, for 3 weeks to measure the added value of the REACH concept. REACH is an EU-funded project within the Horizon 2020 program. The project acronym stands for Responsive Engagement of the Elderly Promoting Activity and Customized Healthcare. The intervention consists of a Kinect-based virtual rehabilitation system (ActivLife) coupled with a rehabilitation machine (Fig. 1). Elderly patients' activities were monitored via an ankle wearable tracker (Stepwatch) (Fig. 1). The study has been approved by the Institution's Ethical Committee (No 2018-01516).

\section{Participants Recruitment}

We recruited the participants from two urban rehabilitation hospitals in a large city in Switzerland. Patients were randomly assigned in the Intervention Group $(N=35)$ of
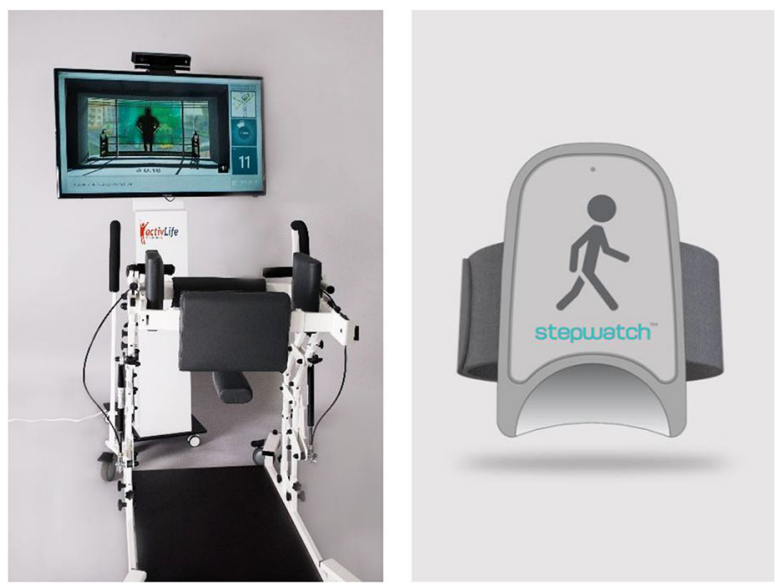

Fig. 1 ActivLife / Stepwatch 
using the gamified rehabilitation equipment 3 times a week or to a Control Group $(N=$ 22) of usual rehabilitation therapies. Our inclusion criteria were: $65+$ years old, hospitalized in one of the involved sites, with musculoskeletal issues (hip fracture, knee or hip prosthesis, falls and low back pain withour vertebral fracture), able to remain standing with help, and understanding the instruction.

\section{Materials}

Participants in the intervention group used two devices: the rehabilitation equipment (ActivLife) and the wearable sensor (Fig. 1). ActivLife allowed the participants to do their exercise via a series of rehabilitation game while Stepwatch measured the evolution of their walking activity during the study.

ActivLife is an activation equipment coupled with a rehabilitation game. The games and the instructions are displayed on a screen in front the patient who is secured in a mechanical platform ActivLife. ActivLife allows to maintain a safe and upright standing position while performing balance, upper limbs and lower limbs exercises. The device is also equipped with a mechanism assisting the patient in standing up. Performing squats with the equipment has been shown to increase muscle strength on the lower parts of the body (Les et al. 2017). The screen has a Kinect sensor that allows the software to determine if the patient is doing the exercise correctly. The software allows the physical therapist to program and schedule a specific treatment (series of rehabilitation games) for each patient.

Stepwatch is a wearable sensor that measures the activity of the patient in terms of number of steps, activity (low, medium, high), cadence and velocity. It is a wearable watch that does not display any information and can be worn on the ankle. Stepwatch demonstrated to capture small changes in step rate (99\% accuracy (Cindy Ng et al. 2012; McCullagh et al. 2016)), thus it can be used to assess changes in physical activity in individuals who walk slowly or use a walking aid such as a rollator. Furthermore, it allows to collect the data locally, which ensure the patient's privacy.

\section{Procedure}

Figure 2 provides an overview on the study procedure.

The hospital electronic medical records of all consecutive new hospitalized patients were accessed (from February to June 2019) to identify potential participants. All patients who fulfilled the eligibility criteria were screened by two medical doctors (in each of the sites) and one nurse. Two researchers then presented the project and provided written information about the study to the identified subjects. If the contacted patient agreed to participate, researchers ask the patient to sign an informed consent form. Participants were then allocated randomly to one of the two arms of the trial. The randomization was based on a single allocation ratio. Due to the intervention type, allocation was not masked to participants in the intervention and control groups or to researchers who recruited patients.

Intervention consisted in five therapies per week: three 30 min therapies using ActivLife and 2 standard physical therapies Participants in the control group wore the Stepwatch sensor and followed usual rehabilitation program, consisting in five standard physical therapies (standard care) per week. The rehabilitation was performed 


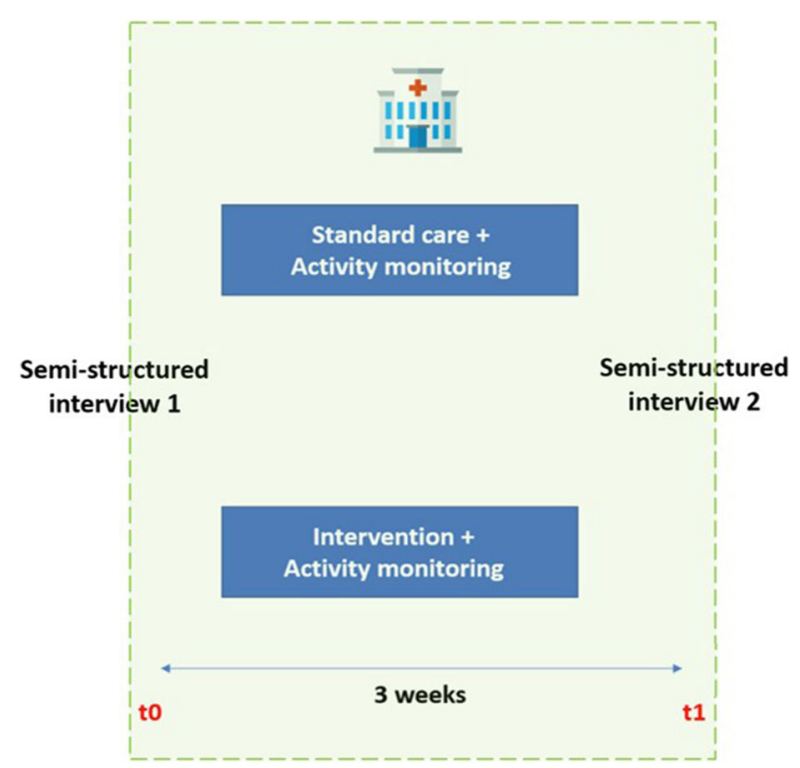

Fig. 2 Research procedure

under the supervision of physical therapists. Both groups were monitored constantly with the Stepwatch sensor and participated in training sessions of 30 min every day.

\section{Assessment}

Semi-structured interviews were conducted to collect older patient's inputs at time t0 (before the intervention) and $\mathrm{t} 1$ (end of the hospitalization). Interviews lasted between $17 \mathrm{~min}$ to $38 \mathrm{~min}$, with a mean of $26 \mathrm{~min}$. Steps data collected by the sensor was coded on collection. Data were collected at the hospital.

\section{Data Analysis}

We audio-recorded all interviews (total of $3990 \mathrm{~min}$ ), transcribed them into English, and analyzed the resulting 546,630 words according to the grounded-theory approach. After reading all the transcripts, one researcher generated a starting list of codes based on the research questions and the patterns that emerged from the data. Another researcher returned to the data and conducted a systematic axial coding to identify emergent themes. After several coding iterations, both researchers identified and categorized the themes and reached a consensus. Orange data mining software and TreeCloud.org were used to visualize interviews results and confirm the coding originally performed by the researchers.

\section{Findings}

Table 1 summarizes the attitudes before the intervention and behavior changes after the intervention. 


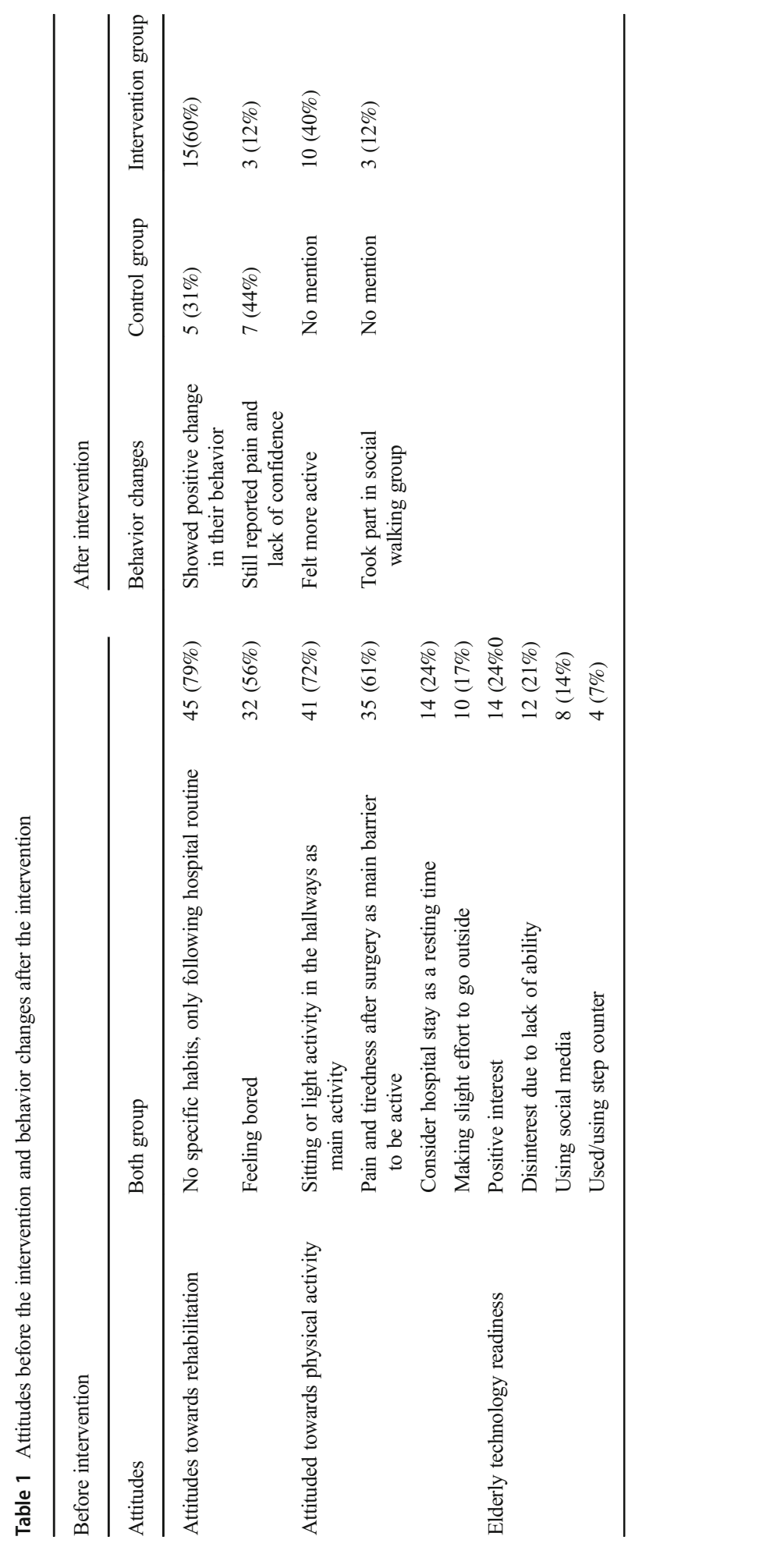




\section{Before Intervention (t0)}

Results from the first semi-structured interview conducted before the intervention are reported here. No distinction between the groups were found. The attitudes observed towards rehabilitation, towards physical activity and towards technology are common for both groups. Participants from intervention group are described with prefix I (I1,.., I35) where as participants from control group are described with prefix $\mathrm{C}(\mathrm{C} 1, \ldots, \mathrm{C} 22)$.

\section{Population Characteristics}

The participants were 39 females (68\%) and 18 males (32\%). Their age ranges between 67 and 95 , with a mean age of $81.5 \pm 6.8$. Two thirds of the participants live alone, and the rest live with their family. Although 6 participate in gymnastics for seniors, most of them indicate moderate walking as their main physical activity. The majority (41) enjoys light activities such as watching TV, reading newspapers, knitting or playing word games as a hobby. News and animal documentaries are the most watched emission. Six of the participants fancy technology and mention it as a distraction to do video and photo editing or follow-up on previous professional activities. One participant gives courses on radio technology and telegraphy. Most of them use landline phones for communication. Twenty-three have smartphones, tablets or computers, and among them, eight use social media applications (WhatsApp®), mostly motivated by their family. Two used a pedometer before but stopped using it due to loss and two uses an application on the phone to monitor activity.

\section{Elderly Attitudes towards Rehabilitation Process}

The geriatric rehabilitation process is often linked to complex care issues involving a panel of health professionals throughout their care path. The participants shared their view on the rehabilitation process at the hospital.

Forty-five patients $(79 \%)$ reported not having any specific habits but only following hospital routine. I3 said "It's the same every day. Days start with morning care, breakfast, toilet, another care... a little bit later there is a physiotherapy session. Not too long after that, it's lunch again. The afternoon is calm. We finish with diner around 6 pm and evening care." C4 mentioned "There are lots of caregivers coming and going all day. It can be tiring sometimes but that's the hospital rhythm, so we follow along." Thirty-two patients (56\%) admitted feeling bored being at the hospital. I8 said "Days here are very monotonous. I wonder what I am doing here." $\mathrm{C} 1$ reported "We are not doing much here, I am a little bored."

\section{Elderly Attitudes towards Physical Activity}

Regarding elderly opinion about physical activity at the hospital, different points of view emerged from the discussion.

Thirty-five patients $(61 \%)$ reported pain and tiredness after the surgery as the main barrier for being active. I6 said "Normally, I am pushed in a wheelchair. However, once I took the rollator to the cafeteria. I shouldn't have because after that I was very tired." C3 stated "I can barely stand up and I find myself shaky. So, I rest regularly in the chair 
or take naps.” I4, I23, C6 reported having pain while trying to walk. I3 mentioned "Sometimes, I try go outside but when I make some effort, it is painful, so I go back to my room." Fourteen patients $(24 \%)$ stated being at the hospital to rest and not to exercise. I33 said "I am a patient, so I stay on my bed. I am here to rest." C1 stated "I am doing nothing here, but this rhythm is fine with me." I24 and I27 reported sleeping a lot due to lack of energy, concentration and motivation.

Forty-one patients (72\%) reported sitting or light walking in the corridor as their main activity at the hospital. C7 said "Yesterday, for the first time, I went all the way down the hall'. I13 mentioned "In the morning, I often sit in the hallways. I play word games or chat with the person next to me." However, ten patients (17\%) stated making the effort to go outside. I8 said "I go outside three times a day because there's nothing to see in the corridor." C10 mentioned "After lunch, I go to the park which is very pleasant, then I sit there to read newspapers." I26 reported "As soon as I can go outside, I'm out. I have pain, but that doesn't stop me from going outside."

\section{Elderly Technology Readiness}

We attempt to understand older adults' attitudes towards innovation. Today, technological solutions are not always tailored to senior citizen's requirements and capacity, which results in a lack of interest on their part (Olphert et al. 2009). However, fourteen patients $(25 \%)$ showed positive interest and were in favor of the progress brought by technology. C2 said "It is so useful because you can get in touch with other people far away from you." I26 mentioned "I am so happy to have my phone. I also have my computer here, it's in the closet. It's a good distraction." I8 added "It's just fantastic. If you look at scanners or MRIs, it became much easier to detect pathologies. Especially, technologies used in healthcare are really useful." Eight participants (14\%) reported actively using social media to communicate with their friends and family. C6 said "My son wanted to teach me how to take pictures, but I didn't need him, I knew how to do it. I use my phone for calls, text messages, calendar and WhatsApp." I2 mentioned "I use WhatsApp and SMS to share videos and news to my family." I3 said "I am on Facebook. I use it a lot. I don't have any privacy concerns because I have a very limited number of friends. I only use WhatsApp to chat with the children." Still, twelve participants (21\%) reported disinterest in technology mainly due to a lack of ability. C7 said "Yes we have internet but it's not for me. I don't know how to use it." C4 mentioned "It can be annoying sometimes when it does not work." I9 stated "In practice, it's catastrophic. I've already demolished computers and thrown them away in the trash because it did not work."

Nine patients $(16 \%)$ heard about pedometer before in different circumstances. C7 said "I've always wanted to have a step counter when I had a dog, but it was quite expensive." I23 reported "Yes I know, it gives your number of steps. I have a friend who walks a lot, occasionally, he wears a pedometer." Four participants (7\%) had previous experience with sensing technology and encountered difficulties. I3 said "I used the step counter in my phone. But, sometimes even if I walk, it shows 0. There is something I am doing wrong maybe." Despite, hearing about sensing technology and serious game for the first time, the majority expressed interest in trying something that could potentially help their rehabilitation. C1 said "I don't mind using them if it's something I really need." I4 stated "Why not? I can be fun" I26 said "If it is useful, then there is no problem." 


\section{Summary}

Before using the different devices, our intent was to understand older patients' attitudes towards the rehabilitation process, their motivation for physical activity as well as their technology readiness. Table 1 summarizes the findings. Participants admitted feeling bored at the hospital and only following along the care process routine. Sitting in the hallways, reading newspapers, playing word games and light walking represents their main activity at the hospital. Pain, lack of energy and motivation after surgery were identified as the main barriers to being active. Furthermore, although some patients $(N=12)$ reported disinterest in technology, mainly due to a lack of ability, the same proportion $(N=14)$ showed enthusiasm and were in favor of the progress brought by technological solution. Interest in trying a tool that could potentially help their rehabilitation was observed.

\section{After Intervention (t1)}

Results from the second semi-structured interview conducted after the intervention (meaning at the end of hospitalization) are reported here. Regarding behavior change after the intervention, we make the distinction between control group and intervention group. The common behavior observed in both groups are: first, positive change such as making the effort to walk outside, second, pain and lack of confidence. The only difference is that we observed more positive change less pain and lack of confidence in the intervention group. In addition, the participants in the intervention group felt more active and participated in social walking groups.

During the study, sixteen participants (Intervention Group =10; Control Group =6) dropped out. Seven wanted to stop, four were transferred to another hospital, three were found not eligible, one left the hospital earlier and one died. Here, we proceed to the analysis of the remaining forty-one participants (Intervention Group =25: Control Group =16). Figure 3 illustrates the patients' flow diagram. Although not statistically significant, the mean number of steps per day (Steps_Intervention_Group $=2375$; Steps_Control_Group=1696) (Table 2) showed that participants from the intervention group were more active during the last week of hospitalization compared to the control group. Three patients from the intervention group VS seven patients from the control group had less than a mean 1000 steps/day during the last week of hospitalization.

\section{Acceptance and Adoption}

Intervention Group At the end of hospitalization, twenty-three patients (92\%) from the intervention group reported positive feedback towards the gamified rehabilitation. They particularly enjoyed the playfulness as it brought back family memory. I6 said "Frankly, I am like a kid. I like to play these games. I really enjoyed it. When I throw balls at cans, it reminds me of my childhood." I23 mentioned "It's nice and funny. It makes me thinks of my grandchildren when they challenge each other." I1 said "The games are funny. If my little ones could see that, they'd be so happy. It's like a child game."

Eighteen patients $(72 \%)$ reported the gamified intervention to be stimulating and challenging. They were curious and motivated to do more. I1 stated "When these pawns were passing by on the screen and I could shoot them all, I was so happy. I told myself, today I did well." I4 mentioned "I was wondering what the next step in the 


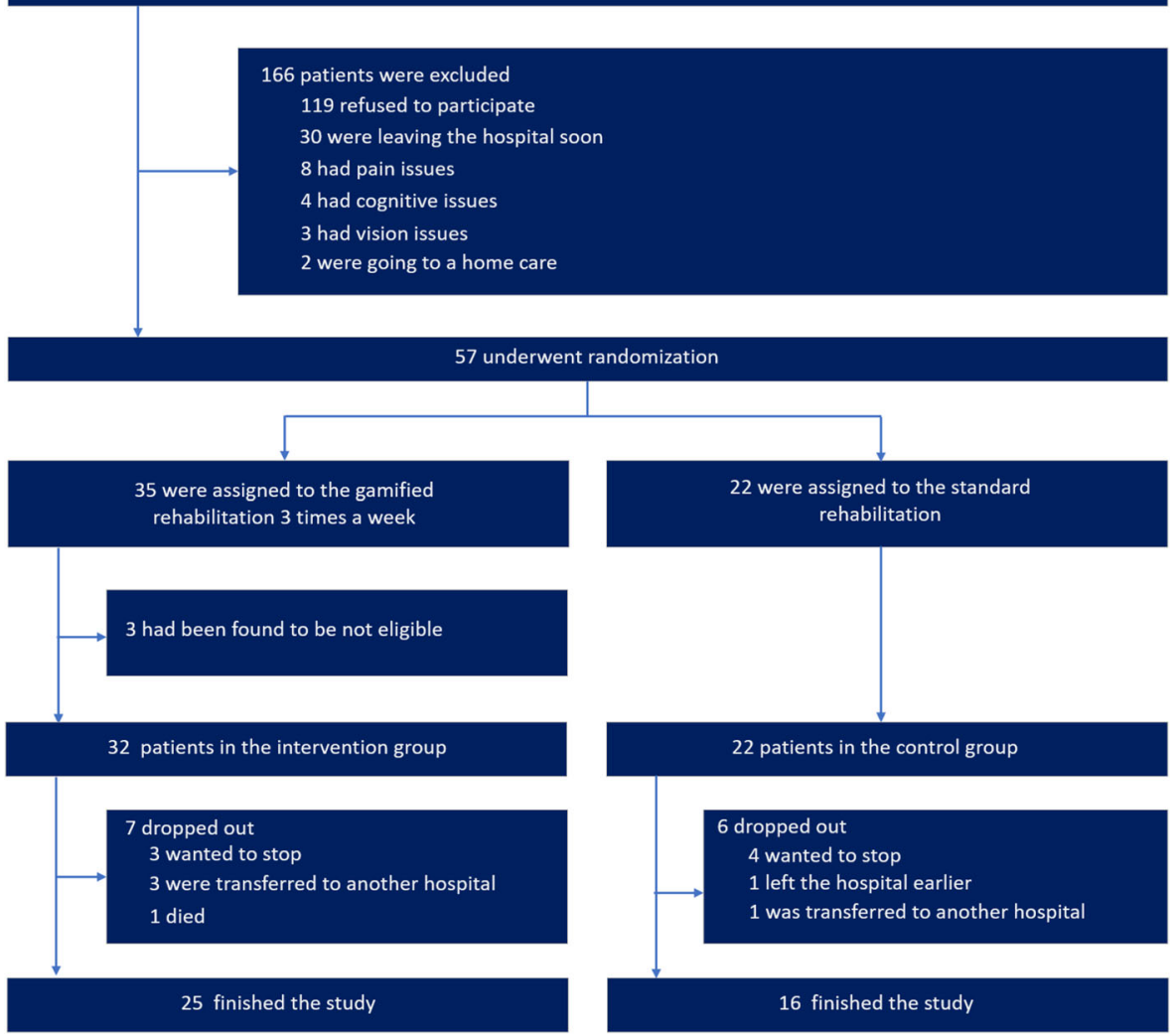

Fig. 3 Patients' Flow Diagram

game was." I8 said "When I take the conventional stairs, I easily stop. But here, there is a challenge. It motivates me. So, I did my best." I3 reported "Yes, it was a motivation, absolutely. I think I would have made less effort if I was doing the standard physiotherapy."

Seventeen patients $(68 \%)$ shared about feeling safe while doing the exercise inside the equipment. I6 said "I did not even worry about safety, it was secure." I24 stated "I felt safe, there is no way I could fall when I am inside the equipment." Few participants, who were still quite weak, felt a bit unstable inside the platform at first, but later gained confidence. I13 reported "At the beginning, I was afraid to fall, so when I went into the equipment, I was afraid too, but later, I gained some stability, so it was fine inside the equipment as well."

Table 2 Mean number of steps per day during the last week of hospitalization

\begin{tabular}{lll}
\hline & $\begin{array}{l}\text { Mean (nb steps/day) during } \\
\text { the last week at the hospital }\end{array}$ & $\begin{array}{l}\text { Nb of patients with less than } \\
\text { mean 1000 steps/day }(\%)\end{array}$ \\
\hline Intervention group $(N=25)$ & 2375 & $3(12 \%)$ \\
Control group $(N=16)$ & 1696 & $7(44 \%)$ \\
\hline
\end{tabular}


Fifteen patients $(60 \%)$ acknowledged that the serious game encouraged self-learning. They felt engaged and more confident in doing the exercise. I4 said "It started with things that seem natural, like cleaning the window. But then, I understood that I must go to the edges, that I should bend down and go up front. Little by little, I got caught up in the game." I18 reported "I loved it. I even dreamt about it at night. Then, I asked the physiotherapist, if I could start cleaning my windows once I get back home, but she told me to wait." I25 stated "As the games progressed, I felt that all my body and my senses were stimulated." I3 was happy to share "I was very studious and rigorous during the exercises. According to the physiotherapist, I am the best here."

Ten patients $(40 \%)$ appreciated the intervention as a nice distraction from the hospital context. I9 said "This made my hospital stay less boring." I4 mentioned "It's a very good idea because, little by little, we lose sight of our disability. It made me forget that I was at the hospital." I1 reported "It was a funny way to make the time pass." I19 added "It was nice. We forgot a bit about our troubles. I liked it."

Even though they enjoyed doing the exercises, twelve patients (48\%) felt exhausted after each session. I22 said "I had a lot of fun but, after a while, I got tired of cleaning the windows with my arms." I27 reported "I was enjoyable but still a little physical, when you really try to do it correctly." I7 stated "It's good, but it's exhausting. For me, the most tiring games were the plane and the ambulance."

Figure 4 illustrates older patients' feedbacks regarding the gamified rehabilitation.

\section{Behavior Change}

Intervention Group At the end of the hospitalization, fifteen patients (60\%) reported a positive change of their behavior at the hospital. They replaced some of their sedentary

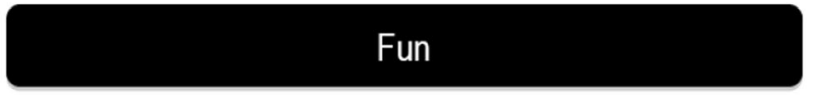

Challenging

Safe

Encouraging self-learning and self-efficacy

Distracting

Exhausting

\section{$92 \%$}

\section{$72 \%$}

$68 \%$

$60 \%$

$40 \%$

$48 \%$

Fig. 4 Patients' feedbacks towards the gamified rehabilitation 
activities such as sleeping, sitting in the hallways or playing word games to going outside and breathing fresh air. I8 said "Sometimes, I go out for a walk in the garden, to take as many steps as I can. It last about an hour." I23 mentioned "I try to move around a bit, it doesn't suit me to be seated all the time." I28 reported "In the afternoon, I circle the park twice. Then, I sit there and read a book. I was never in my room lately." I3 added "We're at the end of our stay here, so I am making some effort to move."

Ten patients (40\%) felt more active and observed significant improvement in their general condition. I22 said "I think I have more confidence now when I walk. A little out of breath though, but I'm less tired than before when I move. I am more active, because there are things, I was afraid to do that I can do now, like walking for example." I9 went through a rapid progression. She started from using a wheelchair, to a walking support, then two canes, and walked without any auxiliary in the end. I6 reported "I feel like I've come a long way back. I'm completely different. I have made a lot of progress and my friends have also really seen the difference. I am more active and much more relaxed."

I4 particularly showed a significant improvement thanks to the pedometer during his hospital stay, as he went from 3000 steps to 9000 steps in just one week. He reported "I'm definitely more active. I feel motivated. When I go in the garden, I make sure I've done my tours, before I sit on a bench to read something. Before all of this, I didn't care about the number of tours I made. I just sat somewhere in the park. But now, my goal has changed as I have this step counter. I want to do more. It's a stimulus. I want to see how many steps I could make if I finish 7 or 8 tours of the garden. When I succeed, I'm satisfied." I4 set a personal goal of doing at least 6 tours of the park every day. After a certain period, he was able to exercise and walk without feeling any constraint. He stated "If I'm given a challenge, I'll play along. I tried to achieve my steps goals without sweating. I wanted to do it naturally. Now, doing 6 tours in the garden has become natural for me. Later, I think, I would make 10,000 steps without any problem, if my leg doesn't hurt."

Three patients (12\%) took part in social activity organized by the hospital motivating them to exercise more. I3 shared "Every Tuesday and Wednesday afternoon I exercise with the walking group. The caregivers proposed me some activity, so I chose what I like." I7 said "I'm walking with a group of people. We exercise and walk together about one hour every week."

However, three patients $(12 \%)$ were not confident enough to engage in daily physical activity during their hospital stay. 122 said "With the rollator, I can go to the dining room by myself, but when I walk with the canes, I still need someone next to me." I24 added "I feel stronger, but I still have this fear of falling. I don't go out alone in the hallways because I'm afraid to lose my balance." I32 reported "I think I've made some progress, but I move considering my fatigue and my need for rest. I'm 87 years old, you know. I feel much less brave."

Control Group At the end of the hospitalization, five patients (31\%) reported positive improvement in their physical activity, which occurred mostly during family visits. $\mathrm{C} 4$ said 'In the morning, I take 30 minutes' walk outside. Sometimes, I just walk to the living room or the cafeteria to see the lunch menu and if there are some interesting cakes. In the afternoon, I have many visitors. Most of the time, I go to the park with 
them." C1 mentioned "Sometimes, I have visitors coming in the afternoon. When the weather was nice, we happen to go for a walk in the sun." C15 stated "I think I'm walking more now. I've been to all the places here: the garden, the library, the dining room and the corridors."

Seven patients (44\%) still reported pain and lack of confidence as barrier to being more active. C6 said 'I'm still feeling pain when I walk but I guess it's normal after surgery. Anyway, I do feel better now. I don't go in the hallways or outside because it's already difficult to walk and come back from the dining room. It's already stressful." C3 stated "I still have pain when I walk. Yesterday, my legs were fluttering". C2 mentioned "At one point, I wasn't feeling so well. Then, we did some exercises rather sitting down."

C24 did not notice any changes in her habits. She appreciated being able to rest during her hospital stay. She shared "I am hyperactive, so I enjoyed doing nothing here."

\section{Summary}

At the end of the hospitalization, our intent was to understand older patients' acceptance and adoption of the gamified rehabilitation equipment and to figure out the behavior changes in both groups. Most of the patients (92\%) from the intervention group, reported a positive feedback towards the serious game-based rehabilitation. The intervention was identified as fun, challenging, allowing self-learning, improving confidence, distracting but also exhausting. Positive change on the behavior at the hospital was observed, mainly from the intervention group. Patients felt more active and observed significant improvement in their general condition. They replaced some of their sedentary activities such as sleeping, sitting in the hallways or playing word games to going outside and breathing fresh air. Few of them engaged in social walking group. However, pain and lack of confidence were still identified as barrier to engage in daily physical activity, mainly from the control group.

\section{Discussion}

Our findings shed light on the older patients' attitudes towards rehabilitation process, their motivation for physical activity as well as their readiness for innovative technology. Acceptance and adoption of serious game-based rehabilitation and the resulting behavior change at the end of the hospital stay were also presented.

\section{Opportunities and Challenges}

Opportunities and challenges for designing serious game-based rehabilitation interventions for elderly emerged from the discussion.

Bachmann et al. (2010) demonstrated in their systematic review the potential of geriatric inpatient rehabilitation to improve functional capacity. However, understanding older patients' perception of the care process during hospitalization remains complex (Krevers et al. 2002). Despite a few numbers of patients who viewed the hospital stay as a resting time, most of our patients perceived the rehabilitation process 
as long, repetitive and boring. This opens an opportunity for gamified rehabilitation designers to propose different solutions aiming at breaking this monotony and improving the recovery process. Using computer games to augment physical and cognitive rehabilitation allows a significant therapeutic benefit as well as a stronger engagement from the patient (Rego et al. 2010). Furthermore, although some patients reported disinterest in technology mainly due to a lack of ability, the same proportion showed enthusiasm and were in favor of the progress brought by the technological solution. In fact, inequalities between the younger and older generation, in terms of accessing the latest technological innovation (Fischer et al. 2014; Hanson 2010), could make it more difficult for the elderly to use them properly. Nevertheless, as the benefits from using information technology arise, such as contacting family and friends or getting medical assistance, a potential long-term adoption of such tools is therefore conceivable (Macedo 2017; Vassli and Farshchian 2018). In our case, interest in trying a solution that could potentially help our patients' rehabilitation were observed.

Understanding the elderly patient's context and characteristics is necessary to design a successful rehabilitation intervention (Barbosa et al. 2018). Most of our participants, reported pain and tiredness after the surgery as the main barrier for being active. Due to the complexity of their health problems, geriatric patients are especially vulnerable (Grimmer et al. 2013) during their rehabilitation. Therefore, gamified solutions need to be customizable enough to adjust to the patient's conditions. In addition, our experiment exposed additional challenges associated to conducting study with older patients in a realworld hospital setting (Mackichan et al. 2013). Subsequent drop-outs (around 30\%) were observed from our study group. They were mainly caused by hospital transfer, loss of eligibility associated to a health conditions decline and a desire to stop participating in the trial. Listening to their doubts and worries as well as emphasizing the benefits of the intervention is therefore necessary to sustain elderly patients' involvements.

\section{Intervention's Impact}

At the end of the hospitalization, most of the patients from the intervention group, reported a positive feedback towards the serious game-based rehabilitation. The intervention was identified as fun, challenging, allowing self-learning, improving confidence, distracting but also exhausting. In addition to the game components, our intervention was composed of an efficient trunk stabilization reassuring the patients while engaging in different movements such as "cleaning the window", "guiding an ambulance" or "flying a dragon" (Kozak et al. 2017). They were therefore encouraged to perform upper limbs exercise in a safe manner.

Although not described in this paper, our serious game-based intervention demonstrated to be as effective as the standard rehabilitation in improving functional capacity of the elderly (Randriambelonoro et al). Additionally, positive change on the behavior at the hospital was observed in both groups but mostly in the group who received the gamified intervention. Patients felt more active and observed significant improvement in their general condition. They replaced some of their sedentary activities such as sleeping, sitting in the hallways or playing word games to going outside and breathing fresh air. Few of them engaged in social walking groups. This explained the reasons why most patients $(88 \%)$ from the intervention group walked more steps (>1000 steps) compared to the control group (56\%). 
Similar results, namely, an improved mood and quality of life of patient with Parkinson's disease, were observed after a one-month usage of the Nintendo Wii (Herz et al. 2013). Also, despite their relatively small sample size, Ma and Bechkoum (2008) shared the benefits of using serious games in movement therapy after stroke. Finally, Hall and al, concluded in their systematic review (Hall et al. 2012) that most of the studies revealed significant positive effects on health outcomes associated with digital videogame play among older adults. Our findings reinforce the potential of serious game-based rehabilitation in engaging elderly patients to be more active.

\section{Design Recommendations}

Based on our findings, we derived four recommended components for serious game-based rehabilitation designers: playfulness, personalization, performance feedback and safety.

\section{Playfulness}

Most of our participants enjoyed playfulness as it brought back family memory. Designers of serious game for elderly should consider involving games that reminds them of their childhood or the time spent with their family, especially their grandchildren. Some participants started to take part in walking groups or reported to go outside mainly with visitors. Fostering social interaction through the game by allowing two or more patients to compete or collaborate side by side, could be a vector of extrinsic motivation to exercise more. Finally, designing incentives related to their hobbies and everyday habits may engage them more in being physically active. As an example, when reaching a certain level through the game, patients could receive clues for their word games.

\section{Personalization}

We recommend a dynamic system, enabling a personalized goal setting, where the game level increases or decreases depending on the patient's improvement and condition. Our participants were eager to know and discover the next of steps in the game. Out of curiosity, some of them even targeted to try all the available games. Depending on the patient's evolution, the game should be easily adaptable and customizable. Additionally, the challenge should be focused on movement precision, especially in the rehabilitation domain. For example, if during the first week, the goal was to make a 90-degree angle with the left arm, the second week the patient could be asked to reach 120-degree angle. In case the patient is feeling pain due to any adverse events, the game level should be downgraded accordingly.

\section{Performance Feedback}

Real time performance feedback is an important component of any gamified intervention. In this specific case, it is even more essential for patients while doing the exercise, to know if they are doing it correctly. Most of our patients reported to be very happy to discover that they have reached their goal. Performance feedback has the potential to bring selfconfidence to the player. Designers should consider implementing visible and easy to understand evaluation of the patient's rehabilitation exercise to increase their self-efficacy. 


\section{Safety}

Safety represents a fundamental aspect to be covered while designing serious games for elderly patients' rehabilitation. All the intervention group patients, in our study, felt safe doing any movements thanks to a trunk stabilization preventing them for falling. However, this could limit the possible range of motion of the patient during the exercise. Designers should propose a safe rehabilitation solution considering the different movements required by the physiotherapist for treating a specific pathology.

\section{Limitations}

Our study presents different limitations. The sample size of the study was small, making it difficult to conclude firmly on the impact of serious game rehabilitation on elderly physical activity. The study duration was also relatively short. Nurse and physiotherapists inputs would also deserve further investigation. Effect after a longterm usage of the gaming components deserves further investigation. Results of the 3weeks follow-up at home will be reported in another paper.

\section{Conclusion}

This paper presents a qualitative analysis of a randomized clinical trial to investigate how older patients are engaged and motivated through a gamified rehabilitation equipment during hospitalization. Before using the different devices, our intent was to understand older patients' attitudes towards rehabilitation process, their motivation for physical activity as well as their readiness for innovative technology. At the end of the hospital stay, our study showed that patients who received the intervention demonstrated stronger engagement in the rehabilitation process and exhibited a higher motivation to be active. Different recommendations on designing serious game for elderly rehabilitation are outlined, especially playfulness, personalization, performance feedback and safety. As our recommendations are based on the specific population of these study the generalization of the results should be confirmed in further research. All in all, our findings suggest the potential short-term impact of serious game-based intervention on elderly motivation for rehabilitation program in a hospital setting.

Acknowledgements This project has received funding from European Union's Horizon 2020 research and innovation program under grant agreement No 690425.

Open Access This article is licensed under a Creative Commons Attribution 4.0 International License, which permits use, sharing, adaptation, distribution and reproduction in any medium or format, as long as you give appropriate credit to the original author(s) and the source, provide a link to the Creative Commons licence, and indicate if changes were made. The images or other third party material in this article are included in the article's Creative Commons licence, unless indicated otherwise in a credit line to the material. If material is not included in the article's Creative Commons licence and your intended use is not permitted by statutory regulation or exceeds the permitted use, you will need to obtain permission directly from the copyright holder. To view a copy of this licence, visit http://creativecommons.org/licenses/by/4.0/. 


\section{References}

Bachmann, S., Finger, C., Huss, A., Egger, M., Stuck, A. E., Clough-Gorr, K. M., et al. (2010). Inpatient rehabilitation specifically designed for geriatric patients: Systematic review and meta-analysis of randomised controlled trials. BMJ, 340, c1718. https://doi.org/10.1136/bmj.c1718.

Barbosa, H., Castro, A., \& Carrapatoso, E. (2018). Serious games and rehabilitation for elderly adults. Global Scientific Journal (GSJ), 6, 275-283.

Brox, E., Konstantinidis, S. T., \& Evertsen, G. (2017). User-centered Design of Serious Games for older adults following 3 years of experience with Exergames for seniors: A study design. JMIR Serious Games, 5(1), e2. https://doi.org/10.2196/games.6254.

Burke, J. W., McNeill, M. D., Charles, D., Morrow, P., Crosbie, J. H., \& McDonough, S. M. (2009). Optimizing engagement for stroke rehabilitation using serious games. The Visual Computer, 25, 10851099. https://doi.org/10.1007/s00371-009-0387-4.

Cindy Ng, L. W., Jenkins, S., \& Hill, K. (2012). Accuracy and responsiveness of the stepwatch activity monitor and ActivPAL in patients with COPD when walking with and without a rollator. Disability and Rehabilitation, 34(15), 1317-1322. https://doi.org/10.3109/09638288.2011.641666.

Consolvo, S., McDonald, D.W., Toscos, T., Chen, M.Y., Froehlich, J., Harrison, B., et al. (2008). Activity sensing in the wild: A field trial of UbiFit garden. In Proc. CHI 2008, ACM Press. https://doi.org/10.1145 /1357054.1357335.

Covinsky, K. E., Palmer, R. M., Fortinsky, R. H., Counsell, S. R., Stewart, A. L., Kresevic, D., et al. (2003). Loss of Independence in activities of daily living in older adults hospitalized with medical illnesses: Increased vulnerability with age. Journal of the American Geriatrics Society, 51, 451-458. https://doi. org/10.1046/j.1532-5415.2003.51152.x.

Cugelman, B. (2013). Gamification: What it is and why it matters to digital health behavior change developers. JMIR Serious Games, 1(1), e3. https://doi.org/10.2196/games.3139.

Deterding, S., Dixon, D., Khaled, R., Nacke, L. (2011). From game design elements to gamefulness: Defining "gamification". Proceedings of the 15th International Academic MindTrek Conference 2011. Tampere, Finland. 9-15. https://doi.org/10.1145/2181037.2181040

El-Hilly, A. A., Iqbal, S. S., Ahmed, M., Sherwani, Y., Muntasir, M., Siddiqui, S., et al. (2016). Game on? Smoking cessation through the Gamification of mHealth: A longitudinal qualitative study. JMIR Serious Games, 4(2), e18. https://doi.org/10.2196/games.5678.

Fischer, S. H., David, D., Crotty, B. H., Dierks, M., \& Safran, C. (2014). Acceptance and use of health information technology by community-dwelling elderly. International Journal of Medical Informatics, 83(9), 624-635. https://doi.org/10.1016/j.ijmedinf.2014.06.005.

Grimmer, K., Beaton, K., Kumar, S., Hendry, K., Moss, J., Hillier, S., Forward, J., \& Gordge, L. (2013). Estimating the risk of functional decline in the elderly after discharge from an australian public tertiary hospital emergency department. Australian Health Review: A Publication of the Australian Hospital Association., 37(3), 341-347. https://doi.org/10.1071/AH12034.

Hall, A. K., Chavarria, E., Maneeratana, V., Chaney, B. H., \& Bernhardt, J. M. (2012). Health benefits of digital videogames for older adults: A systematic review of the literature. Games for Health Journal, 1(6), 402-410. https://doi.org/10.1089/g4h.2012.0046.

Hamari, J., Koivisto, J., \& Sarsa, H. (2014). Does Gamification work? A literature review of empirical studies on Gamification. 47th Hawaii International Conference on System Sciences (HICSS). Waikoloa. 30253034. https://doi.org/10.1109/HICSS.2014.377.

Hanson, V. (2010). Influencing technology adoption by older adults. Interacting with Computers, 22, 502509. https://doi.org/10.1016/j.intcom.2010.09.001.

Herz, N. B., Mehta, S. H., Sethi, K. D., Jackson, P., Hall, P., \& Morgan, J. C. (2013). Nintendo Wii rehabilitation ("Wii-hab") provides benefits in Parkinson's disease. Parkinsonism \& Related Disorders, 19(11), 1039-1042. https://doi.org/10.1016/j.parkreldis.2013.07.014.

Huotari, K., \& Hamari, J. (2012) Defining Gamification - A Service Marketing Perspective. Proceedings of the 16th International Academic MindTrek Conference 2012. Tampere, Finland. 17-22. https://doi. org/10.1145/2393132.2393137.

Idriss, M., Tannous, H., Istrate, D., Perrochon, A., Salle, J. Y., Ho Ba Tho, M. C., et al. (2017). RehabilitationOriented Serious Game Development and Evaluation Guidelines for Musculoskeletal Disorders. JMIR Serious Games, 5(3), e14. https://doi.org/10.2196/games.7284. 
Johnson, D., Deterding, S., Kuhn, K., Staneva, A., Stoyanov, S., \& Hides, L. (2016). Gamification for health and wellbeing: A systematic review of the literature. Internet Interventions, 6, 89-106. ISSN 2214-7829. https://doi.org/10.1016/j.invent.2016.10.002.

Kozak, D., Burgermeister, S., De Chassey, J. D. B., Naef, A., Maringue, A., \& Dietrich, D. (2017). A functionality, safety and validity study of innovative REACH devices. Gerontechnology, 16(3), 181-188. https://doi.org/10.4017/gt.2017.16.3.007.00.

Krevers, B., Närväanen, A. L., \& Öberg, B. (2002). Patient evaluation of the care and rehabilitation process in geriatric hospital care. Disability and Rehabilitation, 24(9), 482-491. https://doi.org/10.1080 /09638280110105268.

Krichevets, A. N., Sirotkina, E. B., Yevsevicheva, E. B., \& Zeldin, L. M. (1995). Computer games as a means of movement rehabilitation. Disability and Rehabilitation, 17(2), 100-105.

Kwok, C. L., Lee, C. K., Lo, W. T., \& Yip, P. S. (2016). The contribution of ageing to hospitalization days in Hong Kong: A decomposition analysis. International Journal of Health Policy and Management, 6(3), 155-164. https://doi.org/10.15171/ijhpm.2016.108.

Lang, C. E., Macdonald, J. R., Reisman, D. S., Boyd, L., Jacobson Kimberley, T., Scindler-Ivens, S. M., et al. (2009). Observation of amounts of movement practice provided during stroke rehabilitation. Archives of Physical Medicine and Rehabilitation, 90, 1692-1698. https://doi.org/10.1016/j.apmr.2009.04.005.

Les, A., Niedzielska, E., Piotrowska, J., Staniszewski, M., \& Kozak, D. (2017). Analysis of the effectiveness of ActivLife training in people over 60 years of age: A pilot study. Gerontechnology., 16(3), 189-119. https://doi.org/10.4017/gt.2017.16.3.008.00.

Liddle, S., Baxter, D., \& Gracey, J. (2007). Chronic low back pain: Patients' experiences, opinions and expectations for clinical management. Disability and Rehabilitation, 29(24), 1899-1909. https://doi. org/10.1080/09638280701189895.

Lin, J.J., Mamykina, L., Lindtner, S., Delajoux, G., \& Strub, H.B. (2006). Fish'n'Steps: Encouraging physical activity with an interactive computer game. Proceedings of the 8 th International Conference on Ubiquitous Computing. 4206. 261-278. https://doi.org/10.1007/11853565_16.

Ling, Y., Ter Meer, L. P., Yumak, Z., \& Veltkamp, R. C. (2017). Usability test of exercise games designed for rehabilitation of elderly patients after hip replacement surgery: Pilot study. JMIR Serious Games, 5(4), e19. https://doi.org/10.2196/games.7969.

Lister, C., West, J. H., Cannon, B., Sax, T., \& Brodegard, D. (2014). Just a fad? Gamification in health and fitness apps. JMIR Serious Games, 2(2), -e9. https://doi.org/10.2196/games.3413.

Lumsden, J., Edwards, E. A., Lawrence, N. S., Coyle, D., \& Munafò, M. R. (2016). Gamification of cognitive assessment and cognitive training: A systematic review of applications and efficacy. JMIR Serious Games, 4(2), e11. https://doi.org/10.2196/games.5888.

Ma, M., \& Bechkoum, K. Serious games for movement therapy after stroke. (2008). IEEE international conference on systems, man and cybernetics. Singapore. 1872-1877. https://doi.org/10.1109 /ICSMC.2008.4811562.

Macedo, I. M. (2017). Predicting the acceptance and use of information and communication technology by older adults: An empirical examination of the revised UTAUT2. Computers in Human Behavior, 75, 935948. https://doi.org/10.1016/j.chb.2017.06.013.

Mackichan, F., Adamson, J., \& Gooberman-Hill, R. (2013). 'Living within your limits': Activity restriction in older people experiencing chronic pain. Age and Ageing, 42(6), 702-708. https://doi.org/10.1093 /ageing/aft119.

McCullagh, R., Dillon, C., O'Connell, A. M., Horgan, F., \& Timmons, S. (2016). Step-count accuracy of 3 motion sensors for older and frail medical inpatients. Archives of Physical Medicine and Rehabilitation, 98(2), 295-302. https://doi.org/10.1016/j.apmr.2016.08.476.

Meekes, W., \& Stanmore, E. K. (2017). Motivational determinants of Exergame participation for older people in assisted living facilities: Mixed-methods study. Journal of Medical Internet Research, 19(7), e238. https://doi.org/10.2196/jmir.6841.

Olphert, W., Damodaran, L., Balatsoukas, P., \& Parkinson, C. (2009). Process requirements for building sustainable digital assistive technology for older people. Journal of Assistive Technologies, 3(3), 4-13. https://doi.org/10.1108/17549450200900019.

Rego, P., Moreira, P.M., \& Reis, L.P. (2010). Serious games for rehabilitation: A survey and a classification towards a taxonomy. 5th Iberian Conference on Information Systems and Technologies. Santiago de Compostela. Pp. 1-6.

Rice, M.D., Sun, M.W.T., Ling, J.N.S, Foo, M.H.N., Janell, K., Sheng, S.L.W., et al. (2011). Evaluating gesture-based games with healthy older adults on a large screen display. CM SIGGRAPH Symposium on Video Games. https://doi.org/10.1145/2018556.2018560. 
Sardi, L., Idri, A., \& Fernández-Alemán, J. L. (2017). A systematic review of gamification in e-health. Journal of Biomedical Informatics, 71, 31-48. https://doi.org/10.1016/j.jbi.2017.05.011.

Skriloff, S., Gonzalez, D., Christensen, K., Bentley, L. \& Mortensen, C. (2016). FitPlay games: Increasing exercise motivation through asynchronous social gaming. Proceedings of the $2016 \mathrm{CHI}$ Conference Extended Abstracts on Human Factors in Computing Systems. 164-167. https://doi.org/10.1145 /2851581.2890367.

United Nations. (2019). Department of Economic and Social Affairs. World Population Prospects 2019: Highlights. https://population.un.org/wpp/Publications/Files/WPP2019_10KeyFindings.pdf Accessed 02 Sept 2019.

Vassli, L. T., \& Farshchian, B. A. (2018). Acceptance of health-related ICT among elderly people living in the community: A systematic review of qualitative evidence. International Journal of Human Computer Interaction, 34(2), 99-116. https://doi.org/10.1080/10447318.2017.1328024.

World Health Organization. (2017). 10 facts on ageing and health. https://www.who. int/features/factfiles/ageing/en/ Accessed 02 Sept 2019.

Publisher's Note Springer Nature remains neutral with regard to jurisdictional claims in published maps and institutional affiliations.

\section{Affiliations}

\section{Mirana Randriambelonoro ${ }^{1,2}$. Caroline Perrin ${ }^{1,2}$ - Alexandra Blocquet ${ }^{3}$ • Dominika Kozak ${ }^{4}$ • Julia Toyas Fernandez ${ }^{3}$. Tiphaine Marfaing ${ }^{3}$ • Elisabeth Bolomey $^{3} \cdot$ Zineb Benhissen $^{3} \cdot$ Emilia Frangos $^{3}$ - Antoine Geissbuhler ${ }^{1,2}$ • Chris- tophe Graf $^{3}$}

1 HI5lab, Department of Radiology and Medical Informatics, Geneva University, Geneva, Switzerland

2 Division of eHealth and Telemedicine, Geneva University Hospitals, Geneva, Switzerland

3 Division of Rehabilitation and Geriatrics, Geneva University Hospitals, Geneva, Switzerland

4 Alreh Medical, Warsaw, Poland 